\title{
Analisis Perencanaan Jaringan Akses Fiber-to- the-Home Berdasarkan Teknologi Gigabit Passive Optical Network (GPON) di STO Banyumanik Semarang
}

\author{
Maria Enggar Santika ${ }^{1}$, Eva Yovita Dwi Utami ${ }^{2}$, Budihardja Murtianta ${ }^{3}$ \\ Program Studi Teknik Elektro, \\ Fakultas Teknik Elektronika dan Komputer, \\ Universitas Kristen Satya Wacana, Salatiga \\ 1612011048@students.uksw.edu, 2eva.utami@staff.uksw.edu, 3budihardja@staff.uksw.edu
}

\begin{abstract}
Ringkasan
Migrasi dari jaringan akses tembaga menuju jaringan akses optik maupun penggelaran baru jaringan akses serat optik menjadi solusi bagi penyedia layanan telekomunikasi untuk memenuhi kebutuhan pelanggan akan layanan suara, data dan video yang terintegrasi atau triple play services. Dalam makalah ini dilaporkan analisis perencanaan jaringan akses serat optik FTTH berbasis GPON di PT Telkom pada Cluster Kruing Raya STO Banyumanik Semarang. Perencanaan jaringan berdasarkan demand pelanggan dan kelayakan jaringan yang digelar diuji menggunakan parameter Link Power Budget, Rise Time Budget dan Signalto-Noise-Ratio (SNR). Dalam perencanaan dan penggelaran dibutuhkan satu ODC (Optical Distribution Cabinet) dan 17 ODP (Optical Distribution Pack) dengan jumlah demand sebesar 132. Hasil perhitungan parameter Link Power Budget yaitu total redaman yang dihasilkan pada user 1 sebesar 21,5276 dB sedangkan user 2 sebesar 21,5276 dB, kedua redaman ini memenuhi standar yang ditentukan oleh PT Telkom yaitu maksimal sebesar $28 \mathrm{~dB}$. Parameter Rise Time Budget pada user 1 menghasilkan 0,2124 ns dan untuk user 2 sebesar 0,21221 ns. Kedua hasil tersebut masih berada di bawah batas nilai waktu sistem NRZ sebesar 0,28011 ns. Parameter SNR pada user 1 didapatkan sebesar 20,6457 dB dan user 2 sebesar 24,128 dB. Hasil tersebut memenuhi batas yang telah ditentukan oleh PT Telkom yaitu lebih dari sama dengan $20 \mathrm{~dB}$.
\end{abstract}

Kata kunci: FTTH, GPON, Link Power Budget, Rise Time Budget

\section{Pendahuluan}

Pada masa sekarang ini terjadi kompetisi layanan akses pita lebar antar operator telekomunikasi. Para penyedia layanan mulai menawarkan layanan "bundled" yang artinya menyediakan layanan suara, data dan video dalam satu paket dengan kualitas layanan yang baik dan cukup dengan satu biaya langganan untuk semua layanan tersebut yang biasanya menjadi lebih murah daripada biaya berlangganan secara terpisah[1]. Untuk menyediakan layanan seperti itu maka PT Telekomunikasi Indonesia, Tbk (PT Telkom) menghadirkan layanan Triple Play Service atau layanan data, suara dan video melewati akses broadband hanya dengan berlangganan satu jenis media koneksi saja. 
Untuk menyalurkan layanan Triple Play Service kepada pelanggan pada awalnya menggunakan teknologi MSAN (Multi Service Access Node) berdasarkan kabel tembaga. Namun teknologi ini semakin kurang optimal karena tembaga memiliki keterbatasan kapasitas dan daya tahannya tidak bisa lebih dari 10 tahun. Untuk penyediaan layanan dengan kapasitas bandwidth yang besar diperlukan migrasi dari jaringan akses tembaga menjadi jaringan akses menggunakan serat optik yang bandwidth-nya dapat mencapai 2,488 Gbps. Atas dasar inilah PT Telkom membangun jaringan akses fiber-to-the-home (FTTH) sehingga dapat mengirim data dengan lebih cepat dan bandwidth yang lebih besar. Salah satu faktor yang mempengaruhi jaringan akses FTTH adalah teknologi yang dipilih, yaitu Gigabit Passive Optical Network (GPON). GPON merupakan teknologi akses data berbasiskan kabel serat optik yang mampu mencapai bit rate hingga 2,5 Gbps. Beberapa layanan yang saat ini sedang dikembangkan adalah IPTV, video conference, interactive game, video on demand yang membutuhkan bandwidth yang besar.

Pada makalah ini dilaporkan hasil perencanaan jaringan FTTH berdasarkan teknologi GPON dan evaluasi terhadap kelayakan jaringan yang digelar di daerah Banyumanik Kota Semarang yaitu pada Cluster Kruing Raya. Penelitian dilakukan dengan mendesain jalur akses dan menentukan perangkat yang akan digunakan. Kemudian jalur akses yang sudah didesain, dianalisis menggunakan Link Power Budget, Rise Time Budget dan S/N untuk menentukan bahwa jaringan yang telah dibangun memenuhi kelayakan jaringan akses optik.

\section{Perencanaan Jaringan FTTH}

Langkah-langkah perencanaan jaringan FTTH dilakukan dalam beberapa tahap. Tahap pertama adalah peninjauan lapangan pada Cluster Kruing Raya untuk mengetahui demand, kebutuhan bandwidth serta boundary Cluster yang akan dipasang jaringan FTTH. Setelah mendapatkan data lokasi, demand dan boundary dilanjutkan dengan perencanaan penentuan perangkat jaringan yang dibutuhkan pada cluster tersebut meliputi kabel yang digunakan, panjang kabel, jumlah perangkat ODC, kapasitas perangkat ODC, jumlah perangkat ODP, jumlah tiang baru, jenis perangkat OLT, port OLT yang dibutuhkan, serta jumlah splitter 1:4 dan 1:8.

Setelah penentuan perangkat jaringan dilanjutkan dengan mengkonfigurasi jaringan FTTH yang diikuti dengan pelaksanaan pembangunan fisik lapangan. Setelah pembangunan fisik lapangan diselesaikan sesuai dengan perencanaan data survei maka dilanjutkan dengan pengukuran data untuk perhitungan parameter yang nantinya akan dievaluasi untuk menentukan kelayakan jaringan yang telah dibangun.

\subsection{Penentuan Lokasi dan Jenis Layanan}

Lokasi yang akan diteliti berada di Jl. Kruing Raya Kecamatan Banyumanik Kota Semarang dengan daerah berupa cluster kelas menengah. Paket yang ditawarkan PT Telkom adalah 10 Mbps sampai dengan 100 Mbps. Paket 10 Mbps biasanya diminati oleh pelanggan rumah pribadi sedangkan untuk paket $10 \mathrm{Mbps}$ ke atas diminati untuk perkantoran, pelanggan bisnis maupun sekolah yang membutuhkan bandwidth skala besar.

\subsection{Tinjauan Lapangan (Survei)}

Survei dilakukan untuk melengkapi data-data sebelum perencanaan dimulai. Pada lokasi yang akan direncanakan jaringan FTTH, dilakukan proses tagging yaitu proses 
Analisis Perencanaan Jaringan Akses Fiber-to-the-Home Berdasarkan Teknologi Gigabit Passive Optical Network (GPON) di STO Banyumanik Semarang Maria Enggar Santika, Eva Yovita Dwi Utami, Budihardja Murtianta

mendeteksi jaringan-jaringan yang telah ada sebelumnya menggunakan GPS. Diawali dengan mencari ODC yang telah ada sebelumnya yang terdekat dengan lokasi perencanaan. Jika posisi ODC terlalu jauh atau belum ada maka harus dibangun ODC baru, dan sebaliknya jika terdapat ODC yang kapasitasnya mencukupi, akan digunakan ODC yang telah ada tersebut. Untuk lokasi Cluster Kruing Raya terdapat ODC tepat di seberang jalan Kruing Raya yang bernama ODC-BMK-FAY dengan kapasitas port yang masih kosong maka ODC tersebut dapat digunakan. Setelah menentukan posisi ODC selanjutnya dilakukan tagging tiang lama yang telah ada yang mengitari Kruing Raya. Tiang lama ini akan menentukan posisi ODP dan juga penambahan tiang baru bila diperlukan. Hasil survei cluster Kruing Raya ditunjukkan pada Tabel 1.

Tabel 1. Hasil Survei

\begin{tabular}{|c|c|}
\hline Demand Cluster Kruing Raya & 132 \\
\hline Jumlah ODC & 1 \\
\hline Kapasitas ODC & 144 port \\
\hline Koordinat ODC & $7^{\circ} 4^{\prime} 11,00^{\prime \prime}$ S dan $110^{\circ} 25^{\prime} 6,83^{\prime \prime} \mathrm{T}$ \\
\hline Nama ODC & ODC-BMK-FAY \\
\hline Jumlah Tiang Lama & 44 \\
\hline
\end{tabular}

\subsection{Perencanaan Rancangan Jaringan FTTH}

Secara umum konfigurasi umum dari jaringan FTTH dapat dilihat pada Gambar 1.

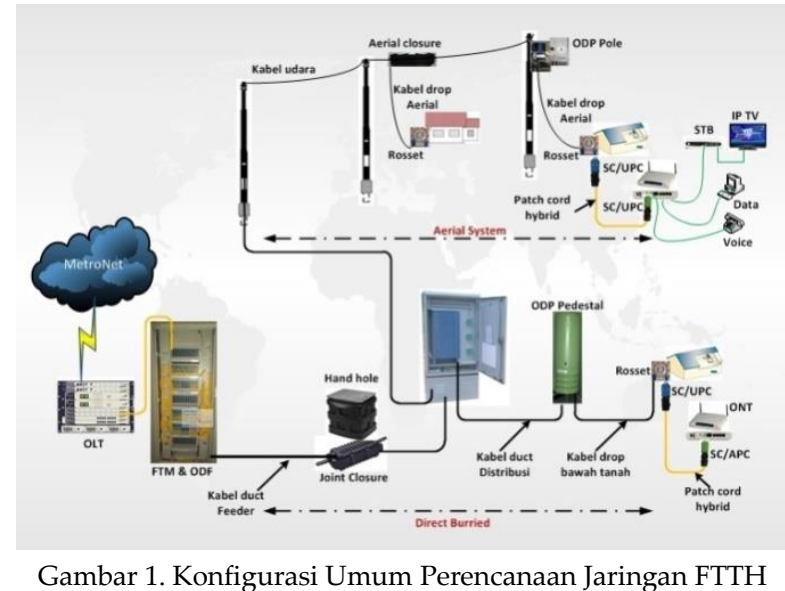

Pada jaringan FTTH terdapat dua jenis konfigurasi, yaitu Aerial System dan Direct Burried. Aerial System menggunakan kabel udara atau kabel yang terpasang pada tiangtiang, demikian juga letak ODP berada di tiang-tiang. Direct Burried menggunakan kabel bawah tanah (duct). Cluster Kruing Raya menggunakan Aerial System karena jaringan yang sudah ada sebelumnya menggunakan kabel udara dan kondisi cluster yang tidak memungkinkan untuk digunakan Direct Burried yaitu kondisi rumah yang terlalu berdekatan dan tidak ada jarak antara jalan dengan rumah.

Titik awal perencanaan dilakukan di Sentral Telepon Otomat (STO) Banyumanik tempat terdapatnya perangkat Optical Line Terminal (OLT) yang berperan sebagai perangkat opto-elektronika yaitu mengubah gelombang cahaya menjadi listrik atau sebaliknya[2]. Dari OLT disambungkan ke Fiber Termination Management (FTM) menggunakan patch core, FTM ini mempunyai fungsi sebagai perangkat monitoring.

Dari OLT dan FTM akan tersambung dengan kabel feeder yaitu kabel serat optik yang menyambungkan antara OLT dengan ODC, kabel feeder ini menggunakan sistem duct. 
Serat optik mempunyai berbagai kapasitas core mulai dari 2 core, 4 core hingga 288 core. Kabel feeder biasanya berkapasitas besar yakni 144 hingga 288 core sesuai dengan kebutuhan merupakan kabel utama STO menuju ODC.

Optical Distribution Cabinet (ODC) merupakan titik terminasi dari ujung kabel feeder dengan pangkal kabel distribusi [2]. Di dalam ODC terdapat beberapa komponen seperti konektor yang berfungsi sebagai penghubung kabel optik. Splitter 1:4 merupakan komponen pasif yang dapat memisahkan daya optik dari input serat ke beberapa output misalnya 1:4 berarti bahwa daya satu input dipisahkan menjadi empat output. Kapasitas ODC antara lain 96 core, 144 core dan 288 core.

Kabel feeder pada ODC di-split (dipetik) semisal 24 core atau 48 core tergantung kapasitas ODC kemudian sisanya akan menuju ODC yang lain. Core feeder yang berada di ODC masuk ke dalam splitter 1:4. Tiap daya input maupun output disalurkan melalui satu kabel serat optik. Seluruh daya output dari ODC tersambung menuju Optical Distribution Pack (ODP) melalui kabel kabel distribusi. ODP merupakan tempat terminasi antara kabel distribusi dengan kabel drop yang akan ditarik ke rumah pelanggan. ODP mempunyai komponen konektor dan splitter 1:8 dan 1:16. Untuk splitter 1:8 maka 1 ODP melayani 8 rumah pelanggan sedangkan jika splitter 1:16 maka 1 ODP melayani 16 rumah pelanggan.

Perangkat di ujung sisi pelanggan pada jaringan FTTH adalah Optical Network Terminal (ONT). ONT ini mengubah sinyal optik yang dipancarkan menjadi sinyal elektrik yang diperlukan untuk service pelanggan [2].

Pada cluster Kruing Raya digunakan splitter 1:4 pada ODC dan splitter 1:8 pada ODP karena lebih efisien untuk mencakup demand yang letaknya jauh dari ODC jika hanya menggunakan splitter 1:32 maka cakupan demand akan terbatas.

\subsection{Desain Jaringan}

Perencanaan jaringan diawali dengan mendesain wilayah cluster Kruing Raya menggunakan aplikasi Google Earth. Berdasarkan survei, diperoleh jumlah demand sebanyak 132. Dengan asumsi jarak antara rumah sebesar $10 \mathrm{~m}$ karena Cluster Kruing Raya termasuk padat penduduk maka dibutuhkan $1320 \mathrm{~m}$ untuk mengitari Cluster Kruing Raya sehingga dibutuhkan 1 distribusi karena 1 distribusi tidak boleh lebih dari $3000 \mathrm{~m}$.

Boundary dari hasil survei yang telah didapat dimasukkan ke dalam Google Earth seperti terlihat pada Gambar 2a. Dengan batas-batas yang telah ditentukan oleh bagian Divisi Access PT. Telkom berdasarkan wilayahnya. Kemudian ditarik garis distribusi mengikuti pola daerah Kruing Raya karena kabel distribusi ini merupakan jalur kabel yang akan melewati demand di Kruing Raya secara keseluruhan

Berdasarkan hasil survei untuk mengitari Kruing Raya yang dimulai dari ujung titik ODC sampai dengan titik pangkal dibutuhkan panjang kabel sebesar $1807 \mathrm{~m}$ dengan toleransi $5 \%$. Toleransi ini untuk mengantisipasi adanya lengkungan antar tiang dan juga jika ada kebutuhan pelebaran jaringan. Hasil tagging tiang lama/yang telah ada sebelumnya diinputkan ke dalam aplikasi Google Earth sehingga didapatkan Gambar 2b.

Karena di jalan Kruing Dalam Timur tidak terdapat tiang lama sampai dengan batas boundary maka di jalan tersebut akan di bangun 2 tiang baru. Jarak antara tiang dalam rentang $40 \mathrm{~m}$ sampai dengan $50 \mathrm{~m}$ untuk lebar per gawang yang ditunjukkan pada Gambar 2c. 
Analisis Perencanaan Jaringan Akses Fiber-to-the-Home Berdasarkan Teknologi Gigabit Passive Optical Network (GPON) di STO Banyumanik Semarang Maria Enggar Santika, Eva Yovita Dwi Utami, Budihardja Murtianta

Untuk menentukan jumlah ODP yang dibutuhkan untuk melayani demand Kruing Raya yang berjumlah 132 pengguna dihitung dari splitter yang terpasang pada tiang ODP. Pada setiap ODP terdapat delapan buah splitter dengan satu splitter digunakan untuk satu rumah pengguna, maka ODP yang dibutuhkan cluster Kruing Raya adalah 17 ODP seperti yang ditunjukkan pada Gambar 2d.

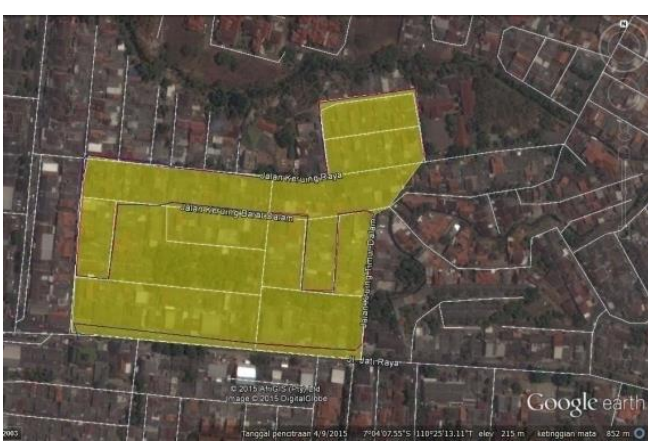

(a)

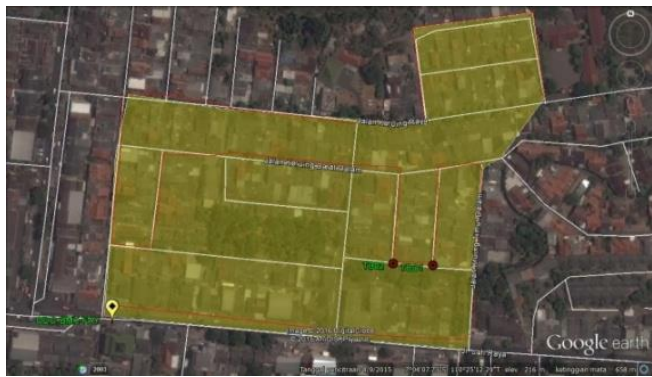

(c)

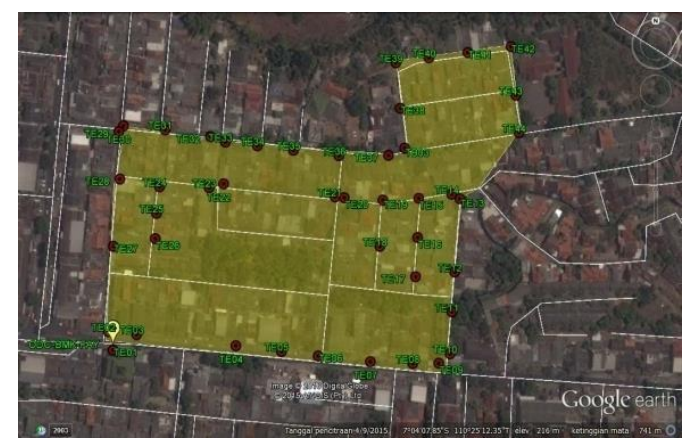

(b)

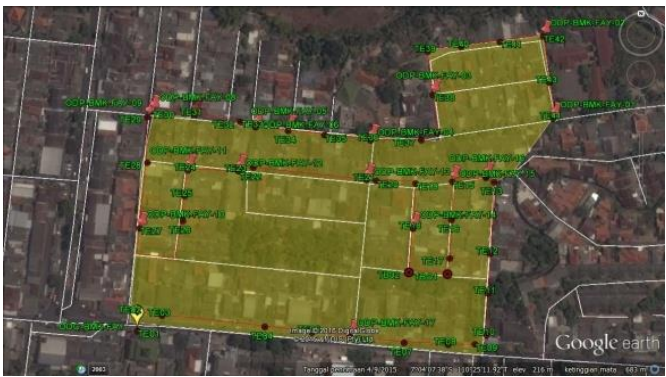

(d)

Gambar 2 Peta Kruing Raya: (a) Boundary Kruing Raya, (b) Tiang yang telah ada sebelumnya, (c) Tiang baru yang dibangun, (d) Titik-titik lokasi ODP

Jadi untuk Cluster Kruing Raya dengan jumlah demand 132 cukup menggunakan 1 jalur distribusi dengan kapasitas 24 core yang berarti maksimal dapat menampung 24 ODP per distribusi, satu ODC lama dengan nama ODC-BMK-FAY, ODP yang berjumlah 17 dan panjang kabel dari ODC sepanjang $1897 \mathrm{~m}$ (sudah termasuk toleransi 5\%).

\subsection{Konfigurasi dan Penentuan Perangkat Jaringan}

Setelah melewati tahap mendesain jaringan Cluster Kruing Raya maka selanjutnya adalah mengkonfigurasi jaringan dan menentukan perangkat jaringan yang akan digunakan dalam perencanaan sebagai berikut.

Dari hasil survei diketahui pada cluster kruing raya menggunakan ODC-BMK-FAY yang telah ada sebelumnya dengan kapasitas 288 core. Pada desain perencanaan jaringan diketahui bahwa untuk cluster Kruing Raya akan menggunakan 17 ODP, tiap 4 ODP yang terpasang akan terterminasi di dalam 1 splitter 1:4 di ODC sehingga 17 ODP menggunakan 5 splitter 1:4.

Berdasarkan ODC-BMK-FAY yang telah ada sebelumnya sudah terterminasi ke dalam OLT Alcatel pada rak yang ke-3. Berdasarkan jumlah port input ODC sebesar 5 buah port maka di OLTpun membutuhkan 5 buah port karena tiap port input dalam ODC akan diterminasi ke dalam 1 port OLT. Port yang tersedia dan dapat digunakan adalah port 9,10,11,12 dan 13 . 
Jenis kabel serat optik yang digunakan untuk jaringan FTTH dari PT Telkom adalah single mode tipe G.652d untuk kabel feeder maupun untuk distribusi. Spesifikasi serat optik tercantum pada referensi [3].

ODP yang digunakan berjumlah 17 ODP seperti yang telah dijelaskan sebelumnya. Setiap ODP terdapat splitter 1:8 karena setiap satu ODP nanti akan melayani delapan demand, berarti untuk melayani 132 demand membutuhkan 17 splitter 1:8.

Perangkat ONT yang digunakan 132 buah sesuai dengan jumlah demand yang berada pada Cluster Kruing Raya. Perangkat ONT diletakkan di dalam rumah pelanggan dan tersambung oleh ODP dengan menggunakan kabel drop. Secara keseluruhan kebutuhan untuk perencanaan FTTH Cluster Kruing Raya terdapat pada Tabel 2.

Tabel 2. Kebutuhan Perencanaan Jaringan

\begin{tabular}{|c|c|c|}
\hline No & Deskripsi & Jumlah \\
\hline 1 & demand & 132 \\
\hline 2 & ODC & 1 \\
\hline 3 & OLT & 1 \\
\hline 4 & ONT & 132 \\
\hline 5 & Jalur distribusi & 1 \\
\hline 6 & Tiang lama & 44 \\
\hline 7 & Tiang baru & 2 \\
\hline 8 & ODP & 17 \\
\hline 9 & Splitter 1:4 & 5 \\
\hline 10 & Splitter 1:8 & 17 \\
\hline 11 & kabel feeder & $1,2 \mathrm{Km}$ \\
\hline 12 & Kabel distribusi & $1807 \mathrm{~m}$ \\
\hline 13 & Konektor & 3 \\
\hline 14 & sambungan & 4 \\
\hline
\end{tabular}

\subsection{Parameter-parameter kelayakan jaringan akses optik}

Untuk menguji kelayakan jaringan optik yang telah dibangun diperlukan pengukura parameter-parameter berikut.

\subsubsection{Link Power Budget}

Link power budget merupakan persyaratan agar pada link yang dirancang dayanya berada di atas ambang daya yang dibutuhkan [4][5]. Untuk mencapai hal ini digunakan persamaan

$$
\begin{gathered}
\alpha_{\mathrm{tot}}=L_{. \alpha s e r a t}+N_{\mathrm{c}} \alpha_{\mathrm{c}}+N_{\mathrm{s}} \alpha_{\mathrm{s}}+S_{\mathrm{p}} \\
P_{\mathrm{r}}=P_{\mathrm{t}}-\alpha_{\mathrm{tot}}-S M \\
M=\left(P_{\mathrm{t}}-P_{\mathrm{r}}\right)-\alpha_{\mathrm{tot}}-S M
\end{gathered}
$$

dengan $P_{\mathrm{t}}$ adalah daya keluaran sumber optik dalam $\mathrm{dBm}, P_{\mathrm{r}}$ adalah daya terima receiver dalam $\mathrm{dBm}, S M$ adalah Safety margin yang nilainya $6 \mathrm{~dB}, \alpha_{\text {tot }}$ adalah redaman total sistem dalam $\mathrm{dB}, L$ adalah panjang serat optik, $\alpha_{\mathrm{c}}$ merupakan redaman konektor dalam $\mathrm{dB}$ per konektor, $\alpha_{\mathrm{s}}$ adalah redaman sambungan dalam $\mathrm{dB}$ per sambungan, $\alpha_{\text {serat }}$ merupakan redaman serat optik dalam $\mathrm{dB} / \mathrm{km}, N_{\mathrm{s}}$ jumlah sambungan, $N_{\mathrm{c}}$ adalah jumlah konektor, $S_{\mathrm{p}}$ adalah redaman splitter dalam $\mathrm{dB}$ dan $\mathrm{M}$ adalah margin.

\subsubsection{Rise Time Budget}

Merupakan metode untuk menentukan batasan dispersi suatu link serat optik serta menganalisa sistem transmisi digital. Rise Time Budget dapat dihitung dengan [5][6] 
Analisis Perencanaan Jaringan Akses Fiber-to-the-Home Berdasarkan Teknologi Gigabit Passive Optical Network (GPON) di STO Banyumanik Semarang Maria Enggar Santika, Eva Yovita Dwi Utami, Budihardja Murtianta

$$
\begin{gathered}
t_{\text {sys }}=\sqrt{t_{t x}^{2}+t_{\text {mat }}^{2}+t_{\text {intermodal }}^{2}+t_{r x}^{2}} \\
t_{\text {mat }}=\Delta \sigma \times L \times D m \\
t r=\frac{0,7}{B r}
\end{gathered}
$$

dengan $t_{\mathrm{tx}}$ adalah rise time sumber cahaya, $t_{\text {mat }}$ adalah rise time dispersi material, $t_{\text {intermodal }}$ adalah rise time dispersi intermodal, $t_{\mathrm{rx}}$ adalah rise time receiver, kesemuanya dalam $\mathrm{ns}, B_{\mathrm{r}}$ adalah bit rate dalam $\mathrm{ns}, \Delta \sigma$ adalah lebar spektral dalam $\mathrm{nm}, L$ adalah panjang serat optik dalam $\mathrm{km}$ dan $D_{\mathrm{m}}$ adalah dispersi material dalam ps/nm.Km.

Umumnya degradasi total waktu transmisi dari link digital yang dijinkan adalah tidak melebihi 70 persen dari satu periode bit untuk data NRZ (Non-Return-to-Zero) atau 35 persen dari satu periode bit untuk data RZ (Return-to-Zero). Satu periode bit didefinisikan sebagai resiprokal dari data rate.

\subsubsection{Signal to Noise Ratio}

Signal-to-noise-ratio (SNR). merupakan perbandingan antara daya sinyal terhadap daya derau pada satu titik yang sama, dinyatakan sebagai [7]

$$
S N R=\frac{\text { daya } \operatorname{sinyal}}{\text { daya derau }}
$$

\section{Hasil dan Pembahasan}

Perencanaan jaringan FTTH untuk Cluster Kruing Raya meliputi penentuan konfigurasi jaringan dan analisa kinerja jaringan. Konfigurasi jaringan ditunjukkan dengan jaringan menggunakan 2 splitter yaitu splitter 1:4 dan splitter 1:8. Panjang kabel transmisi terjauh yang diukur dari STO Banyumanik sampai dengan cluster Kruing adalah 3,079 $\mathrm{Km}$. Perhitungan bandwidth yang dibutuhkan pelanggan mengacu pada jenis layanan yang dibutuhkan pelanggan dalam hal ini adalah layanan data, layanan suara, dan layanan video atau triple play. Paket yang ditawarkan oleh PT.Telkom untuk cluster kruing adalah 10 Mbps. Sehingga jika semua pelanggan menggunakan semua jenis layanan triple play maka total bandwidth yang dibutuhkan adalah 1,320 Gbps.

\subsection{Parameter Link Power Budget}

Perhitungan link power budget dilakukan untuk mengetahui batasan redaman total yang diijinkan antara daya keluaran pemancar dan sensitivitas penerima. Perhitungan ini berdasarkan standarisasi ITU-T pada Referensi [2] dan juga peraturan yang diterapkan oleh PT.Telkom yaitu jarak tidak lebih dari $20 \mathrm{~km}$ dan redaman total tidak lebih dari 28 dB. Berdasarkan Persamaan (1), (2) dan (3) maka didapatkan hasil pada Tabel 3.

Tabel 3. Pengujian Link Power Budget

\begin{tabular}{|c|c|c|}
\hline Deskripsi & User 1 & User 2 \\
\hline Redaman Total $\left(\alpha_{t o t}\right)$ & $21,5276 \mathrm{~dB}$ & $21,0396 \mathrm{~dB}$ \\
\hline Daya Terima $\left(P_{r x}\right)$ & $-24,1256 \mathrm{dBm}$ & $-23,6376 \mathrm{dBm}$ \\
\hline Margin Daya & $0,8744 \mathrm{~dB}$ & $1,3624 \mathrm{~dB}$ \\
\hline
\end{tabular}

Nilai total redaman yang telah dihitung di atas masih di bawah nilai redaman maksimal yang ditentukan oleh [2], maka link optik ini memenuhi syarat dari sisi redaman total. 
Nilai $\operatorname{Prx}_{\mathrm{rx}}$ harus lebih besar atau sama dengan sensitivitas detektor atau daya maksimal yang dapat diterima oleh receiver agar dapat bekerja dengan baik. Pada hasil perhitungan membuktikan bahwa jaringan optik yang telah terpasang dengan daya awal $3,402 \mathrm{~dB}$ telah memenuhi syarat perangkat yang digunakan oleh PT.Telkom yaitu di atas $-28 \mathrm{dBm}$

Nilai margin harus berada di atas 0 (nol) $\mathrm{dB}$. Oleh karena itu hasil perhitungan nilai margin sebesar 0,8744 $\mathrm{dB}$ pada user 1 dan 1,3624 $\mathrm{dB}$ pada user 2 telah memenuhi kelayakan link power budget.

\subsection{Parameter Rise Time Budget}

Rise time budget diperlukan untuk tujuan menganalisis kemampuan komponen sistem yang dirancang dapat menjamin bahwa sistem yang didesain dapat mentransmisikan bit rate layanan. Rise time budget pada kebal optik single mode ini sangat perlu dilakukan karena adanya keterbatasan akibat pengaruh dispersi pada saluran transmisi optik. Output akhir dari analisis Rise Time Budget ini sebagai ukuran unjuk kerja jaringan yang dirancang layak atau tidak diimplementasikan. Berdasarkan spesifikasi alat dan menggunakan Persamaan (4)-(6) diperoleh nilai rise time pada Tabel 4.

Tabel 4 Hasil Pengujian Rise Time Budget

\begin{tabular}{|c|c|c|}
\hline Deskripsi & User 1 & User 2 \\
\hline tmaterial & $0,0107765 \mathrm{~ns}$ & $0,00589645 \mathrm{~ns}$ \\
\hline Rise time sistem & $0,2124 \mathrm{~ns}$ & $0,21221 \mathrm{~ns}$ \\
\hline
\end{tabular}

Dari perhitungan didapatkan nilai tsys adalah sebesar 0,2124 ns untuk user 1 dan 0,21221 ns untuk user 2. Nilai ini memenuhi batasan waktu di bawah 0,28011 ns untuk pengkodean NRZ. Berdasarkan hasil tersebut dapat disimpulkan bahwa sistem memenuhi kelayakan rise time budget

\subsection{Signal To Noise Ratio}

Dalam menentukan kualitas transmisi, digunakan paramater signal to noise ratio (SNR). Berdasarkan Persamaan (7) diperoleh hasil pengujian untuk parameter SNR pada Tabel 5.

Tabel 5. Hasil Pengujian Signal to Noise Ratio

\begin{tabular}{|c|c|c|}
\hline Deskripsi & User 1 & User 2 \\
\hline Daya terima & $3,8676 \times 10^{-6}$ watt & $5,8026 \times 10^{-6}$ watt \\
\hline Signal Power & $4,897 \times 10^{-11} \mathrm{~A}$ & $11,0226 \times 10^{-11} \mathrm{~A}$ \\
\hline Noise & $4,22040 \times 10^{-13} \mathrm{~A}$ & $4,26064 \times 10^{-13} \mathrm{~A}$ \\
\hline SNR & $20,6457 \mathrm{~dB}$ & $24,128 \mathrm{~dB}$ \\
\hline
\end{tabular}

Dari hasil pengujian yang telah didapatkan maka hasil-hasil di atas dibandingkan dengan standar kelayakan yang telah ditentukan oleh PT Telkom sebagaimana ditunjukkan pada Tabel 6. Berdasarkan standard PT Telkom, hasil pengujian yang telah memenuhi standar kelayakan. 
Analisis Perencanaan Jaringan Akses Fiber-to-the-Home Berdasarkan Teknologi Gigabit Passive Optical Network (GPON) di STO Banyumanik Semarang Maria Enggar Santika, Eva Yovita Dwi Utami, Budihardja Murtianta

Tabel 6. Hasil Pengujian Sistem

\begin{tabular}{|c|c|c|c|c|}
\hline \multirow{2}{*}{ Deskripsi } & \multirow{2}{*}{ Standart } & \multicolumn{2}{|c|}{ Hasil pengujian } & \multirow{2}{*}{ Evaluasi } \\
\hline & & User 1 & User 2 & \\
\hline Total Redaman & $\leq 28 \mathrm{~dB}$ & $21,5276 \mathrm{~dB}$ & $21,0396 \mathrm{~dB}$ & Sesuai \\
\hline Daya yang diterima & $\geq-28 \mathrm{dBm}$ & $-24,1256 \mathrm{dBm}$ & $-23,6376 \mathrm{dBm}$ & Sesuai \\
\hline Margin Daya & $0<$ & $0,8744 \mathrm{~dB}$ & $1,3624 \mathrm{~dB}$ & Sesuai \\
\hline \multicolumn{5}{|c|}{ Memenuhi Kelayakan link Power Budget } \\
\hline tsystem & $\leq 0,28011 \mathrm{~ns}$ & $0,2124 \mathrm{~ns}$ & $0,21221 \mathrm{~ns}$ & Sesuai \\
\hline \multicolumn{5}{|c|}{ Memenuhi Kelayakan Rise Time Budget } \\
\hline SNR & $\geq 20 \mathrm{~dB}$ & $20,6457 \mathrm{~dB}$ & $24,128 \mathrm{~dB}$ & sesuai \\
\hline
\end{tabular}

\section{Kesimpulan}

Berdasarkan hasil analisis perencanaan, pengujian dan pengukuran lapangan maka dapat disimpulkan hal-hal berikut. Perencanaan jaringan FTTH di Cluster Kruing Raya Banyumanik Semarang menghasilkan konfigurasi jaringan yang terdiri dari empat komponen utama yakni Optilcal Line Termination (OLT), Splitter 1:4, Splitter 1: 8 dan Optical Network Termination (ONT). Digunakan splitter 1:4 dan 1:8 pada perencanaan ini karena kombinasi splitter ini dapat menjangkau letak user yang jauh dari ODC sedangkan jika menggunakan splitter 1:32 atau 1:16 user yang letaknya jauh tidak terjangkau sehingga diperlukan ODC baru. Hasil perencanaan jaringan FTTH di Cluster Kruing Raya membutuhkan 17 ODP dengan ODC lama yang telah ada dengan nama ODC-BMKFAY. Sehingga total jaringan yang disediakan ada 136 sedangkan demand yang ada berjumlah 132 jadi jaringan yang disediakan telah mencukupi demand yang ada. Hasil pengukuran dan pengujian telah memperlihatkan parameter link power budget, rise time budget dan signal-to-noise-ratio telah memenuhi standar kelayakan jaringan akses serat optik.

\section{Daftar Pustaka}

[1] S. Jain, P.K. Verma, "IMS-IPTV Moving Together", 13th International Conference on Intelligence in Next Generation Networks (ICIN) 2009, 2009

[2] Telecommunication Standardization Sector ITU-T, ITU-T Recommendation G 984.1: Gigabit-capable passive optical networks (GPON): General characteristics, 03/2008

[3] Direktorat Network dan Solution PT Telekomunikasi Indonesia, Tbk., Pedoman Instalasi dan Pedoman Pemasangan Jaringan Akses Fiber Optik, Bandung, 2010

[4] R.J. Hoss, "Fiber Optic Communication Design Handbook", Prentice-Hall International, Inc., 1990

[5] Z Ghassemlooy, Optical Fibre Communication Systems [Online] http://soe.northumbria.ac.uk/ocr/teaching/fibre/pp/system/ diakses 31 Juli 2016

[6] G. Keiser, “Optical Fiber Communication 2nd Ed.”, McGraw-Hill, Inc., 1991

[7] F.G. Stremler, "Introduction to Communication Systems 3rd edition", Addison Wesley, 1990 
